\title{
Deslegitimação das diferenças étnicas, "cidanização" e desamortização das terras de índios: notas sobre liberalismo, indigenismo e leis agrárias no México e no Brasil na década de 1850*
}

\section{Vânia Maria Losada Moreira*}

\begin{abstract}
Resumo: Neste artigo, busco refletir sobre a desamortização das terras indígenas no Brasil, durante a segunda metade do século XIX, por meio de uma abordagem comparativa com o caso mexicano no mesmo período. Na primeira parte do texto, discuto a "nacionalização" e a "cidanização" dos índios como um processo inicialmente muito mais imposto pela ação estatal do que reivindicado por eles. $\mathrm{Na}$ segunda, problematizo a desamortização das terras indígenas no âmbito do ideário liberal e das leis agrárias de ambos os países. Procuro demonstrar que a desamortização exerceu uma pressão dissociativa sobre as comunidades indígenas e isso reiterava e acelerava a política de "nacionalização" e "cidanização" dos índios.
\end{abstract}

Palavras-chave: Índios; Desamortização de terras indígenas; Cidanização.

\begin{abstract}
This study provides a reflection on disentitlement of indigenous lands in Brazil during the second half of the $19^{\text {th }}$ Century through a comparative approach with the Mexican case in the same period. In the first part, "nationalization" and "citenization" of indigenous peoples are discussed as a process initially more imposed by state action than claimed by them. The second part addresses the problem of disentitlement of indigenous lands within the liberal outlook and agrarian laws of both countries. This study shows that disentitlement produced a dissociative pressure on indigenous communities, which reaffirmed and sped the policy on "nationalization" and "citenization" of natives.
\end{abstract}

Keywords: Natives; Disentitlement of indigenous lands; Citenization.

A partir da Independência, em 1822, e ao longo do regime imperial (1822-1889), as diretrizes políticas de feitio liberal tenderam a se fortalecer no novo cenário político brasileiro e, no que tange à questão indígena, a propugnar mais ostensivamente a rápida assimilação social dos índios à sociedade imperial. Visível na implacável política de deslegitimação das comunidades étnicas, que impôs aos seus membros, às vezes de maneira violenta e outras de forma mais negociada, o estatuto jurídico e político de "brasileiros" e "cidadãos", o processo de "nacionalização" e "cidanização" da população indígena alcançou níveis decisivos a partir da segunda metade do século XIX. ${ }^{1}$ Nesse período, iniciou-se a

\footnotetext{
* Este texto é parte de uma pesquisa financiada pela FAPERJ e foi originalmente publicado em espanhol em OHMSTEDE, Antonio Escobar; JONG Ingrid de (comps). Las poblaciones indígenas en la construcción y conformación de las naciones y los estados en la América Latina decimonónica. México: CIESAS México D.F., 2012 (en prensa).

** Professora associada no Departamento de História da Universidade Federal Rural do Rio de Janeiro - UFRRJ.

${ }^{1}$ José Murilo de Carvalho sublinha que, com a Constituição de 1824, o estado outorgou "de cima para baixo" o título de cidadão a toda população livre do Império, prevendo, no entanto, critérios de renda para classificá-los como "ativos" e "passivos", i.e., com ou sem direitos de participar do cenário político-eleitoral. A extensão da cidadania à população livre não foi, portanto, uma resposta do estado às reivindicações e lutas dos setores sociais subalternos,
} 
desamortização das terras dos índios, deslanchada em ritmo firme com a promulgação da Lei de Terras de 1850, dos seus regulamentos, em 1854, e de uma série de avisos e leis complementares, cujo objetivo precípuo era o de acabar com o domínio e o uso comum sobre várias terras que eles possuíam na forma de sesmarias, missões, aldeamentos, compras e doações. No mesmo período, percebe-se um movimento semelhante no processo histórico mexicano, também impactado por um conjunto de reformas de corte liberal que atingiram os pueblos indígenas e que culminaram em um progressivo processo de privatização das terras públicas (baldios) e comunais, impulsionadas pela lei de 1856, mais conhecida como Lei Lerdo.

O objetivo deste texto é o de refletir sobre a desamortização das terras indígenas durante a vigência do regime imperial no Brasil e, para isso, proponho uma abordagem comparativa com o caso mexicano. Por meio da observação das similaridades e diferenças entres dois ou mais fenômenos, a aplicação da abordagem comparativa na historiografia pode servir para alcançar diferentes objetivos intelectuais. ${ }^{2}$ Do ponto de vista dessa reflexão, contudo, a comparação entre México republicano e Brasil imperial tem valor e função fundamentalmente heurística, no sentido de permitir a identificação de questões e problemas correlacionados com o processo de desamortização das terras indígenas na segunda metade do século XIX que, de outro modo, podem continuar pouco visíveis ou negligenciados.

A meta é a de comparar certos objetivos políticos subjacentes às leis agrárias de ambos os países, problematizando a questão indígena e as terras dos índios à luz do ideário liberal e dos projetos nacionais então em gestação tanto no México quanto no Brasil. O método comparativo implica, no entanto, seleção dos aspectos a serem analisados e isso termina por exigir uma dose de abstração e de simplificação dos contextos histórico-sociais. Para a história, que é uma disciplina ciosa em relação aos "contextos", isso pode afigurar-se como uma limitação. Mas, tendo em mente o potencial heurístico da comparação e de seu "eye-opening effect" ${ }^{3}$, creio ser válido o empreendimento aqui proposto.

O texto está dividido em duas partes: na primeira, discuto a "nacionalização" e a "cidanização" da população indígena no México e no Brasil como processos muito mais impostos pela ação estatal a essas populações do que inicialmente reivindicado por elas. Trata-se, portanto, de um fenômeno político e ideológico primeiramente operado "de cima para baixo" e que procuro relacionar com outro, de natureza mais econômica, representado pela desamortização e privatização das terras dos índios. Isso não quer dizer, naturalmente, que os índios não tenham, ao longo do processo histórico, se apropriado do vocabulário político da época segundo seus próprios interesses e projetos. No caso do Brasil, ademais,

mas antes uma estratégia de cooptação e controle social. Cf. CARVALHO, José Murilo de. Dimensiones de la ciudadanía en el Brasil del siglo XIX. In: SABATO, Hilda (coord). Ciudadanía política y formación de las naciones. Perspectivas históricas de América Latina. México: FCE/ COLMEX/ FHA, p. 321-344, p. 325. Não é demais notar, além disso, que a carta de 1824 não fez nenhuma distinção entre "brasileiros" e "cidadãos" em termos de direitos e deveres, embora, na prática, nem todo "brasileiro" fosse efetivamente tratado, percebido ou nomeado como "cidadão" com plenos direitos.

${ }^{2}$ KOCKA, Jürgen. Comparison and beyond. History and Theory, n. 42, p. 39-44, 2003, p. 40.

${ }^{3}$ Ibidem, p. 41 
existem evidências importantes de que na qualidade de "cidadãos" muitos deles aprenderam a reivindicar terra, liberdade e outros tópicos de seus interesses. ${ }^{4} \mathrm{Na}$ segunda, discuto as leis agrárias de ambos os países, promulgadas na década de 1850 , e o processo de desamortização das terras dos índios propriamente dito. Procuro frisar, além disso, que no Brasil a política de desamortização das terras indígenas exerceu uma pressão dissociativa sobre as comunidades indígenas e isso reiterava e acelerava a política de "nacionalização" e “cidanização" dos índios.

\title{
IGUALDADE JURÍDICA E DESLEGITIMAÇÃO DAS DIFERENÇAS ÉTNICAS
}

Na historiografia sobre o México, está bastante assente que as leis agrárias do período pós-independência foram fortemente influenciadas pela concepção de mundo ventilada na Constituição gaditana de 1812. Nela está presente o ideal liberal e individualista sobre a organização da sociedade que, ao legislar sobre a igualdade jurídica dos indivíduos, terminou por levantar a polêmica sobre a necessidade de individualização da propriedade. Sob a influência de Cádiz, a elite liberal mexicana criticou a chamada "república dos índios", pregando a necessidade de acabar com a separação e as diferenças entre índios e mexicanos por meio do estabelecimento da igualdade de todos os cidadãos perante a lei. Aboliu-se, por isso, o tributo pago exclusivamente pela população indígena, durante o período colonial, substituindo-o por uma tributação pessoal que recaia sobre todos os maiores de 16 anos. Além disso, cada estado da federação começou a editar leis com o objetivo de dividir, distribuir e individualizar as terras dos pueblos de índios e camponeses até que, em 25 de junho de 1856, foi instituída a chamada Lei Lerdo, de âmbito nacional, que ordenou a repartição e a privatização das terras das corporações civis e religiosas. ${ }^{5}$ De acordo com Antonio Escobar Ohmstede:

\begin{abstract}
Las leyes liberales emanadas de Cádiz no solo se enfocaron en los derechos del hombre y del ciudadano, sino también en fortalecer el papel del individuo, y es aquí donde el control corporativo de la tierra causaba ciertos atrasos en la consecusión del ideal liberal. Los intentos de entregar en propriendad o en usufructo las tierras de los pueblos a las cabezas de familia, iba en el sentido de formar una sociedad sustentada en indivíduos y no en colectividades. ${ }^{6}$
\end{abstract}

É no marco das transformações das estruturas materiais e mentais desencadeadas pelo fortalecimento do ideário liberal que a historiografia sobre o México tem enfrentado a questão dos pueblos e terras indígenas. Para Antonio Escobar Ohmstede e Ana María Gutiérrez Rivas, por exemplo, a urdidura dos vários projetos estatais que visavam à divisão,

\footnotetext{
${ }^{4}$ MOREIRA, Vânia Maria Losada. De índio a guarda nacional: cidadania e direitos indígenas no Império (vila de Itaguaí, 1822-1836). Topoi, Rio de Janeiro, vol. 11, n. 21, p. 127-142, 2010.

${ }^{5}$ OHMSTEDE, Antonio Escobar. Introducción - La "modernización" de México a través del liberalismo. Los pueblos indios durante el juarismo. In: OHMSTEDE, Antonio Escobar (coord.). Los pueblos indios en los tiempos de Benito Juárez. México: Universidad Autónoma Metropolitana/Universidad Autónoma Benito Juárez de Oaxaca, 2007, p. 929, p. 19.

${ }^{6}$ Ibidem, p. 17.
} 
repartição e privatização das terras dos índios, tinha por base e justificativa o ideal liberal da igualdade jurídica dos indivíduos e o projeto político de criação de uma "nação de cidadãos"7. E, desse novo ponto de vista nacional e liberal, as categorias "índio" e "comunidade" perderam sua razão de ser numa alusão de que os "índios" deveriam desaparecer para renascer como "mexicanos". Bastante exemplar dessa perspectiva foi o decreto de 15 de abril de 1831, que substituía a palavra "indígena" por "mexicanos de antiga origem", sustentando, contudo, que eles tinham pleno direito de domínio e propriedade sobre suas terras, podendo vendê-las ou hipotecá-las a quem quer que fosse. ${ }^{8}$

Daniela Marino lança uma luz especialmente esclarecedora sobre os novos desafios impostos aos índios pela maré liberal, durante o Oitocentos, ao dividir o processo de expropriação e privatização das terras dos pueblos indígenas em dois momentos fundamentais: o primeiro, verificado na primeira metade do século XIX, caracterizou-se pela instituição da igualdade político-jurídica, quando foi desconstruída a legitimidade das diferenças étnicas da população, e os pueblos indígenas passam por um processo de municipalização, perdendo sua organização tradicional e a autonomia política que gozavam no antigo regime colonial. ${ }^{9} \mathrm{O}$ segundo aconteceu a partir da promulgação da Lei Lerdo, em 1856, quando se alterou o regime de posse, propriedade e registro das terras, desencadeando um intenso processo de desamortização e de privatização das terras indígenas. $^{10}$

Até a instituição da igualdade jurídica e do processo de municipalização, os pueblos indígenas eram considerados entidades corporativas legalmente reconhecidas e caracterizavam-se por possuir igreja, terras inalienáveis e governantes indígenas eleitos anualmente. ${ }^{11}$ Essa organização social e política permitiu aos habitantes índios dos pueblos uma relativa autonomia para gerir os assuntos coletivos, inclusive a gestão das terras adjudicadas ao pueblo. As reformas de inspiração liberal aboliram as restrições de moradores não índios nos pueblos de índios, instituíram a igualdade de direitos entre todos os moradores e, como resultado, transformaram os pueblos em comunidades políticas multiétnicas. Com o passar do tempo, no entanto, a historiografia reconhece que os moradores não indígenas passaram a monopolizar, de forma crescente, a governança local, inclusive a gestão das terras que passaram para a jurisdição das novas municipalidades. ${ }^{12}$

A municipalização dos pueblos de índios não foi um processo linear ou igual em todas as regiões, nem tampouco rápido e menos ainda simples e pacífico, pois os princípios liberais sobre como organizar a vida coletiva encontraram a resistência das comunidades

\footnotetext{
${ }^{7}$ OHMSTEDE, Antonio Escobar; RIVAS, María Gutiérrez. El liberalismo y los pueblos indígenas en las Huastecas. In: OHMSTEDE, Antonio Escobar (coord.). Los pueblos indios en los tiempos de Benito Juárez. México: Universidad Autónoma Metropolitana/Universidad Autónoma Benito Juárez de Oaxaca, 2007, p. 253-198, p. 259.

${ }^{8}$ Ibidem, p. 262.

9 MARINO, Daniela. La municipalización: ¿expropriación y privatización de los pueblos de indios por el estado? Generalización en torno del caso de Huixquilucan (siglo XIX). In: SANDOVAL, María del Carmen Salinas; GARDIDA, Diana Birrichaga; OHMSTEDE, Antonio Escobar (coords.). Poder y gobierno local en México. México: Colegio de Michoacán, 2011, p. 351-374, p. 353.

${ }^{10}$ Ibidem, p. 355.

${ }^{11}$ Ibidem, p. 356.

12 Ibidem, p. 354.
} 
locais ainda bastante arraigadas nas práticas e costumes do Antigo Regime. Mas, como frisa Daniela Marino, a modernização política dos pueblos de índios terminou por ampliar a comunidade política municipal, estendendo aos novos moradores, além disso, o acesso aos recursos econômicos locais, notadamente o direito de uso das terras. ${ }^{13}$ Isso preparou o terreno para que os novos moradores, como cidadãos e "vecinos"14, adquirissem a plena propriedade de parte das terras dos pueblos, quando adveio a legislação agrária e desamortizadora da segunda metade do século XIX.

Os aldeamentos de índios no Brasil também passaram por um lento processo de municipalização, com resultados semelhantes ao que, grosso modo, aconteceu no México com os pueblos de índios. ${ }^{15}$ Ainda no período colonial, as reformas pombalinas da década de 1750 deram um primeiro passo nessa direção, transformando muitos aldeamentos em vilas e povoados, onde os luso-brasileiros obtiveram permissão para formar casas de vivenda e obter aforamentos de terra e onde os índios passaram a ter o direito de exercer os cargos da governança local, especialmente os de vereador e juiz ordinário. ${ }^{16} \mathrm{O}$ direito dos índios sobre as terras situadas nas novas vilas e povoados continuou sendo reconhecido pela Coroa Portuguesa, segundo o argumento de que eles eram os primeiros e naturais habitantes do Brasil. Por isso mesmo, mandou-se demarcar as terras que pertenciam aos índios nas novas vilas e povoados, passando-lhes novas cartas de sesmarias ${ }^{17}$.

Do ponto de vista normativo, as câmaras das vilas recém-criadas nos antigos aldeamentos não tinham jurisdição para administrar as terras dos índios. A despeito disso,

\footnotetext{
${ }^{13}$ Ibidem, p. 366.

${ }^{14}$ De forma muito mais acentuada do que no Brasil, a condição de "vecino" (vizinho) é especialmente importante para compreender a configuração da cidadania no México oitocentista porque, ao longo do século XIX, "[...] los derechos políticos se le reconocen sólo a quien tiene status de vecino [...]". Cf. CARMAGNANI, Marcello; CHÁVES, Alicia Hernández. La ciudadanía orgánica mexicana, 1850-1910. In: SABATO, Hilda (coord). Ciudadanía política y formación de las naciones. Perspectivas históricas de América Latina. México: FCE/ COLMEX/ FHA, 1999, p. 371-404, p. 373. Sobre a construção da cidadania no Brasil no mesmo período, ver CARVALHO, Op. cit. GRAHAM, Richard. Ciudadanía y jerarquia en el Brasil esclavista. In: SABATO, Hilda (coord). Ciudadanía política y formación de las naciones. Perspectivas históricas de América Latina. México: FCE/ COLMEX/ FHA, 1999, p. 345-370. GRINBERG, Keila. O fiador dos brasileiros. Cidadania, escravidão e direto civil no tempo de Antonio Pereira Rebouças. Rio de Janeiro: Civilização Brasileira, 2002. MATTOS, Hebe. Raça e cidadania no crepúsculo da modernidade escravista. In: GRINBERG, Keila; SALLES, Ricardo (orgs.). O Brasil Imperial - Volume III - 1870-1889. Rio de Janeiro: Civilização Brasileira, 2009, p. 15-38.

${ }^{15}$ Não é demais esclarecer a diferença entre as "aldeias" originais dos índios e as "aldeias" (ou "aldeamentos") criadas pelos portugueses para fixá-los e controlá-los durante o período colonial. Alguns autores insistem, por isso mesmo, na necessidade de usar o termo "aldeamento" para os estabelecimentos criados pelos portugueses, para deixar a palavra "aldeia" reservada privativamente para designar os estabelecimentos anteriores ou posteriores à conquista, mas que sempre pertenceram exclusivamente aos índios. Cf. ALENCASTRO, Luiz Felipe de. $O$ trato dos viventes. A formação do Brasil no Atlântico Sul. São Paulo: Companhia das Letras, 2000, p. 120. Os aldeamentos eram, portanto, povoações criadas a partir de transferências, mais ou menos forçadas, de homens, mulheres e crianças de suas aldeias originais para lugares próximos dos povoados luso-brasileiros. Essas transferências eram conhecidas como "descimentos". Depois das reformas pombalinas, na década de 1750, muitos aldeamentos foram transformados em vilas, onde os luso-brasileiros obtiveram permissão de morar e aforar terras.

${ }^{16}$ LOPES, Fátima Martins. Em nome da liberdade: as vilas de índios do Rio Grande do Norte sob o Diretório pombalino no século XVIII. Recife: Tese (Doutorado em História). Universidade Federal de Pernambuco, 2005, p. 70.

${ }^{17}$ Carta regia dirigida ao Vice-rei Conde dos Arcos, em que se Ihe ordena a execução do antecedente alvará e o estabelecimento do governo civil dos Indios e que fizesse erigir em villas e logares, com as denominações das terras do Reino, as aldeias que eram habitadas pelos referidos Indios. Belém, 8 de maio de 1758. In: Brasil. Projeto Resgate Barão do Rio Branco. Catálogo Eduardo de Castro Almeida, doc. 3634.
} 
em muitas vilas de maioria indígena, os senados das câmaras tenderam a administrar as terras dos índios e aforá-las como se fossem terras da vila, criando uma profunda sobreposição entre direitos e jurisdições. Esse processo é particularmente visível nas vilas de índios do Espírito Santo, cujas terras passam a ser aforadas pelas câmaras ainda no período colonial $^{18}$, tornando-se uma prática cada vez mais ostensiva e contrária aos interesses dos nativos, na proporção em que eles perdiam para os moradores não índios os cargos da governança e na medida em que aumentava a população forânea na vida social e política local. ${ }^{19}$ A partir de 1875 , contudo, essa prática foi finalmente legalizada por uma lei que permitiu às câmaras municipais venderem e aforarem as terras dos antigos aldeamentos de índios. $^{20} \mathrm{Em}$ resumo, muitos aldeamentos foram transformados em vilas e povoados multiétnicos ainda no período colonial e, progressivamente, os índios perderam os cargos da governança local, bem como o controle sobre suas terras, que, em muitos casos, estava de fato sendo gerida e administrada pelas câmaras, em um processo bastante semelhante ao descrito por Daniela Marino sobre o México.

O Brasil independente nasceu como "planta exótica" na América, segundo a expressão de Joaquim $\mathrm{Nabuco}^{21}$, instituindo o regime monárquico constitucional e mantendo a dinastia de Bragança no poder. Isso tem feito com que a historiografia sobre os índios e a política indigenista do período fique muito mais atenta às continuidades coloniais no Império do que às novidades liberais e nacionalistas que progressivamente caracterizaram o indigenismo oficial do novo regime. Para Carlos de Araújo Moreira Neto, por exemplo, na "análise da política indigenista brasileira durante o século XIX, é indispensável ter em mente [...] que esta representa a continuidade natural da tradição colonial portuguesa". ${ }^{22}$ Por isso mesmo ele qualifica o Primeiro Reinado (1822-1831) como um período no qual a política indigenista não teria perfil próprio, pois seria um momento caracterizado pelo continuísmo colonial na legislação, nos métodos indigenistas e nos quadros políticos, que eram os mesmos do príncipe regente D. João. ${ }^{23}$

Escapa ao autor que a instalação do novo regime fez circular mais facilmente as ideias políticas emanadas de Cadiz, que passaram a ser consideradas e parcialmente apropriadas também pelas elites no Brasil $^{24}$, remodelando, dentre outros setores da vida nacional, o indigenismo do período. Em dois manifestos políticos redigidos no contexto da Independência, por exemplo, a palavra "liberalismo" já servia para indicar uma nova ordem

\footnotetext{
${ }^{18}$ Certidão dos termos de diversos arrendamentos que o ouvidor Francisco de Salles Ribeiro mandou fazer a diferentes possuidores de terrenos pertencentes ao termo da vila de Nova Benavente, ao tempo de sua fundação. Benavente, 23 de fevereiro de 1798. In: AHU, ACL, CU, 005-01, cx. 93, doc. 18.208.

${ }^{19}$ MOREIRA, Vânia Maria Losada. Nem selvagens nem cidadãos: os índios da vila de Nova Almeida e a usurpação de suas terras durante o século XIX. Dimensões - Revista de História Ufes. Vitória, n. 14, p. 151-168, 2002.

${ }^{20}$ CUNHA, Manuela Carneiro da. Legislação Indigenista no Século XIX". In: CUNHA, Manuela Carneiro da (org.). História dos índios no Brasil. São Paulo: Companhia das Letras, 1992, p. 133-154, p. 146.

${ }^{21}$ SALLES, Ricardo. Nostalgia Imperial: a formação da identidade nacional no Brasil do Segundo Reinado. Rio de Janeiro: Topbooks, 1996, p. 41.

${ }^{22}$ MOREIRA NETO, Carlos de Araújo. Os índios e a ordem imperial. Brasília: CGDOC/FUNAI, 2005, p. 27.

${ }^{23}$ Ibidem, p. 247.

${ }^{24}$ NEVES, Lúcia Maria Bastos P. Liberalismo político no Brasil: ideias, representações e práticas (1820-1823), In: GUIMARÃES, Lúcia Maria Pacchoal; PRADO, Maria Emília (orgs.). O liberalismo no Brasil imperial. Rio de Janeiro: Renavan, 2001, p. 73-102, p. 86.
} 
social e política em oposição ao Antigo Regime. ${ }^{25} \mathrm{Na}$ mesma época, José Bonifácio de Andrada e Silva, autor de um dos manifestos citados anteriormente, redigiu também um importante documento sobre a questão indígena, depois apresentado à Assembleia Constituinte do Império, intitulado Apontamentos para a civilização dos índios bravos do Império do Brasil. ${ }^{26}$

Resumidamente, Bonifácio propôs um programa de conquista e ressocialização da população indígena considerada "brava" e, como argumentei em outro texto, a importância desse documento não reside tanto em apresentar proposições novas - já que várias de suas sugestões vinham da experiência colonial -, mas de combinar diferentes experiências coloniais com vistas a alcançar o objetivo de formar e desenvolver uma "nação" forte e etnicamente homogênea no Brasil, inaugurando, desse modo, o indigenismo propriamente nacional. ${ }^{27}$ A proposta de Bonifácio era a de criar aldeamentos como espaços de educação, ressocialização ("civilização") e catequese dos índios, facilitando, contudo, a miscigenação dos índios com "brancos" e "mulatos". A médio e longo prazo, o objetivo era a "nacionalização" e a "cidanização" dos índios, pois a meta, segundo ele, era "misturar as raças, ligar os interesses recíprocos dos índios com a nossa gente, e fazer deles todos um só corpo da nação, mais forte, instruída e empreendedora [...]". ${ }^{28}$

Em 1823, nos trabalhos da Assembleia Constituinte, a questão dos índios veio à baila quando se iniciou a discussão sobre o capítulo que definiria quem seriam os cidadãos do novo Império do Brasil, sendo que nesse debate fica mais claro como a questão da igualdade foi pensada em relação aos índios. O problema de fundo da discussão era se índios poderiam ser considerados "membros da sociedade brasileira" e, por conseguinte, "cidadãos brasileiros", ou se, ao contrário, eram apenas "habitantes" do Brasil. ${ }^{29}$ A opinião dominante era a de que existiam dois tipos de índios no território do Brasil imperial - os índios "bravos" e os "domesticados" - e que cada tipo exigia uma política específica. Para os deputados, o tipo "bravo", "selvagem" ou "tapuia" não poderia ser considerado parte da sociedade, pois não era sequer súdito do estado. Por isso mesmo, a inclusão dos índios ("tapuias") no capítulo da Constituição que definiria quem seria considerado "cidadão" era algo considerado absurdo para alguns deles. O mesmo não era válido para o tipo "domesticado" ou "civilizado", como argumentou o deputado França:

Agora pergunto eu, um Tapuia é habitante do Brasil? É. Um Tapuia é nascido no Brasil? É. Um Tapuia é livre? É. Logo é cidadão brasileiro? Não, [...] pois os Índios no seu estado selvagem não são, nem se pode considerar como parte da grande família Brasileira; e são todavia livres, nascidos no Brasil, e nele habitantes. Nós, é verdade, que temos a Lei que Ihes outorgue os Direitos de Cidadão, logo que eles

\footnotetext{
${ }^{25}$ Ibidem, p. 89.

${ }^{26}$ SILVA, José Bonifácio de Andrada e. Apontamentos para a civilização dos índios bravos do Império do Brasil”. In: CALDEIRA, Jorge (org.). José Bonifácio de Andrada e Silva, São Paulo: Ed. 34, 2002 [1823], p. 183-199.

${ }^{27}$ MOREIRA, 2010a, p. 129;

${ }^{28}$ SILVA, Op. cit., p. 198,

${ }^{29}$ MOREIRA, 2010a, p. 131.
} 
abracem nossos costumes, e civilização, antes disso porém estão fora de nossa Sociedade. ${ }^{30}$

O reconhecimento de que os "tapuias" não faziam parte (ainda) do pacto político do período não é o mesmo que dizer que os deputados estavam negando aos índios o acesso à condição de cidadão, tal como é postulado por certas interpretações historiográficas. ${ }^{31}$ Existia, de fato, uma corrente política e ideológica favorável à exclusão dos índios do novo pacto político, prescrevendo a guerra de extermínio contra grupos recalcitrantes e a imposição aos grupos submetidos à soberania do Império uma espécie de servidão. ${ }^{32}$ Seu principal porta-voz era Francisco de Adolfo Varnhagen, mas não se deve perder de vista que essa nunca foi a orientação da política indigenista oficial do Império, embora, na prática, muitos grupos indígenas tenham sido exterminados e os remanescestes sujeitados a condições muito próximas ao do cativeiro. ${ }^{33}$

Por razões políticas, a Constituinte foi dissolvida e na Constituição outorgada por D. Pedro I, em 1824, os índios não foram mencionados em nenhum parágrafo. Isso significou a ausência de um capítulo especial na nova carta sobre a ressocialização ("civilização") dos índios "bravos", tal como esperava Bonifácio e outros constituintes. Tal questão, aliás, só seria retomada pelo Estado Imperial bem mais tarde, em 1845, quando o governo de D. Pedro II (1840-1889) promulgou o Regulamento das missões de catequese e civilização dos índios (decreto n. 426, de 24 de julho de 1845), para lidar com a inconclusa tarefa de trazer os povos indígenas independentes para o "grêmio da civilização" 34 .

$\mathrm{Na}$ Constituição de 1824, a cidadania foi restringida à população livre. Assim, enquanto escravos crioulos, i.e, nascidos no Brasil, e escravos africanos ficaram inequivocamente excluídos da categoria de "cidadãos", porque eram fundamentalmente classificados como propriedade de outrem, no novo regime a situação dos índios ficou, no máximo, mal definida. A política indigenista durante o Primeiro Reinado (1822-1831) foi, contudo, bastante clara e coerente em relação aos índios, pois aqueles considerados "bravos" deveriam ser sujeitados a um processo de ressocialização, tal como aconteceu com os botocudos do Espírito Santo, que receberam um regulamento específico, recomendando seu "aldeamento" e "civilização". Já os "civilizados" deveriam ser subordinados às leis gerais do Império, tal como ocorreu com os índios da vila de Itaguaí, na província do Rio de Janeiro, que foram nominados de "cidadãos", orientando-se, além disso, que as leis gerais thes fossem aplicadas. ${ }^{35}$

A disposição política de tratar de modo diferenciado índios tidos como ressocializados daqueles que viviam segundo os próprios costumes é ainda muito mais clara

\footnotetext{
${ }^{30}$ Apud. Ibidem, p. 131.

${ }^{31}$ Cf. SLEMIAN, Andréa. Seriam todos cidadãos? Os impasses na construção da cidadania nos primórdios do constitucionalismo no Brasil (1823-1824). In: JANCSÓ, István (org.). Independência: história e historiografia. São Paulo: Hucitec, 2005, p. 829-847, p. 840.

${ }^{32}$ MOREIRA, 2010a, p. 130.

${ }^{33}$ MOREIRA NETO, Op. cit., p. 42.

${ }^{34}$ MOREIRA, 2010a, p. 132.

${ }^{35}$ Ibidem, p. 132.
} 
e visível na política indigenista do Segundo Reinado (1840-1889), especialmente na legislação agrária do período. A Lei de Terras de 1850 (lei n.o 601, de 18/09/1850) e suas regulamentações (decreto n. 1.368 , de 30/01/1854) representam a legislação agrária mais importante do regime imperial brasileiro. ${ }^{36}$ No caso dos índios, ademais, acrescenta-se também a existência de um conjunto de leis, regulamentos e avisos complementares à lei n.o 601, especialmente a Decisão n.o 92, de 21 de outubro de 1850, e a lei n.o 1.114, de 27 de setembro de 1860, cujo objetivo precípuo era o de desamortizar as terras indígenas. ${ }^{37}$

Tomando isoladamente a Lei de Terras e seus regulamentos de 1854 , os direitos territoriais indígenas foram não apenas sumariamente simplificados em relação ao corpo normativo colonial, como especialmente direcionado aos índios definidos como "selvagens". O princípio de que os índios eram "senhores de suas fazendas" - tanto nos sertões quanto nos novos aldeamentos criados para eles -, em razão de serem os "primeiros e naturais" habitantes do Brasil, foi um traço perene no corpo normativo editado sobre os índios, durante o período colonial. O direito a terra, baseado no "indigentato", i.e., no fato de os índios serem os "primeiros e naturais" habitantes das terras do Brasil ${ }^{38}$, é bastante atenuado na Lei de Terras de 1850, que se limitou a recomendar, em seu artigo 12, que se reservassem terras devolutas para a "colonização indígena" ${ }^{39}$. No decreto n.o 1.368 , de 30 de janeiro de 1854, definiu-se com maior clareza o significado e o alcance da "colonização indígena", afirmando-se, no artigo 72, que seriam "reservadas terras devolutas para a colonização e aldeamento de indígenas nos distritos onde existirem hordas selvagens". ${ }^{40}$

O uso do termo "colonização" no texto legal para se referir aos índios representa uma mudança importante no discurso jurídico sobre os direitos dos índios. Naquele momento, a expressão estava fortemente associada à política de incentivo à imigração europeia, por meio da criação dos chamados "núcleos coloniais" para localizar as famílias que se dispusessem a migrar para o Brasil, e às estratégias do governo imperial no sentido de preparar a transição do trabalho escravo para o livre no país. ${ }^{41}$ A "colonização indígena" assegurada pela nova lei agrária aproximava os índios da situação dos estrangeiros e isso só foi possível porque se ignorou o direito de domínio dos índios baseado no "indigenato", um princípio que fora objeto de detida discussão no mundo cristão desde os primeiros momentos da conquista da América. ${ }^{42}$

Os índios tidos com plenamente ressocializados passaram a ser definidos, a partir da Lei de Terras, como "índios só de nome", "índios misturados" à população geral, ou ainda

\footnotetext{
${ }^{36}$ Lei n. 601, de 18/09/1850 e decreto n. 1.368, de 30/01/1854". In: VASCONCELLOS, J. M. P. de. Livro das terras ou coleção da Lei, Regulamentos e ordens. 4. a ed. Rio de Janeiro: H. Lammert \& C., 1885.

${ }^{37}$ Decisão n. 92 de 21/10/1850 e lei n.o 1.114, de 27/09/1860". In: CUNHA, Manuela Carneiro da (Org.). Legislação Indigenista no Século XIX: uma compilação. São Paulo: Edusp, 1992b.

${ }^{38}$ MENDES JÚNIOR, João. Os indígenas do Brazil, seus direitos individuais e políticos. São Paulo: Typ. Hennies Irmão, 1912, p. 58.

${ }^{39}$ Lei n. 601 , de 18/09/1850. In: VASCONCELLOS, Op. cit.

${ }^{40}$ Decreto n.o 1.368, de 30/01/1854. In: Ibidem.

${ }^{41}$ SILVA, Lígia Osório. Terras devolutas e latifúndios. Efeitos da lei de 1850. Campinas: Ed. UNICAMP, 1996, p. 132.

${ }^{42}$ MENDES JÚNIOR, Op. cit. CUNHA, Manuela Carneiro. Os direitos dos índios: ensaios e documentos. São Paulo: Brasiliense, 1987. VITÓRIA, Francisco de. Os índios e o direito da guerra. Ijuí: Editora Unijuí, 2006.
} 
"'mestiços", "remanescentes" ou "descendentes" de índios ${ }^{43}$, em uma clara alusão de que para ser considerado um "verdadeiro índio", a partir de então, os indivíduos e as comunidades deveriam viver isolados em regiões ainda não colonizadas ou apresentar sinais diacríticos contundentes. Para os grupos ou indivíduos tidos como ressocializados, o novo corpo normativo impôs-Ihes a condição de "brasileiros", mandando desamortizar as terras coletivas existentes em vilas e em aldeamentos e reparti-las aos "remanescentes" e "descendentes", caso ainda existissem. Também foi recomendada a regularização do direito de posse e propriedade de antigos foreiros e invasores (posseiros) das terras de índios. ${ }^{44}$ Quanto às terras não cultivadas, deveriam ser consideradas "devolutas", i.e., "vagas" e, portanto, "públicas". Por isso mesmo, deveriam retornar aos próprios nacionais e o estado ficava autorizado a reparti-las, vendê-las ou aforá-las.

Estudos recentes têm rastreado a influência desamortizadora da Lei de Terras nas diferentes províncias do Império e demonstrado situações variadas. Por exemplo, certos grupos conseguiram, inicialmente, registrar suas terras com domínio e posse em comum, como aconteceu nas províncias do Ceará ${ }^{45}$ e do Espírito Santo ${ }^{46}$, enquanto outros grupos tiveram suas terras completamente tomadas pelas ações pública e privada. ${ }^{47}$ Aspecto importante a ser salientado, contudo, é o de que a permanência dos índios e das comunidades indígenas em suas terras ficou cada vez mais a reboque da avaliação das autoridades e dos poderes locais, responsáveis pela aferição do nível de integração e de ressocialização dos índios na cultura dominante. De acordo com Isabelle Braz Peixoto da Silva, por exemplo, um dos fatores importantes para se entender o processo de expropriação dos índios do Ceará foi o critério de "indianidade" utilizado pelas autoridades, que geralmente restringia à categoria de "índio" e o direito às terras indígenas aos tipos humanos "bravios" ou "aldeados" ${ }^{48}$. Os índios moradores em vilas e povoados multiétnicos tenderam a não ser mais considerados "índios" e ficaram, por isso, muito mais vulneráveis aos processos de expropriação.

\section{LEIS AGRÁRIAS E DESAMORTIZAÇÃO}

De acordo com a historiografia sobre o México, a pressão política no sentido de repartir e privatizar as terras indígenas dos pueblos ganhou força no cenário mexicano especialmente depois da Lei Lerdo, que mandou privatizar os bens da Igreja e também os terrenos de común repartimiento dos pueblos, i.e., as terras de posse comum plantadas e manejadas por famílias ou grupos específicos. Isentava-se da obrigatoriedade da

\footnotetext{
${ }^{43}$ CUNHA, 1992 (a ou b??), p. 146.

${ }^{44}$ Ibidem, p. 145

${ }^{45}$ VALLE, Carlos Guilherme Octaviano do. Terra, índios e caboclos em foco: o destino dos aldeamentos indígenas no Ceará (século XIX). In: OLIVEIRA, João Pacheco de (org.). A presença indígena no Nordeste. Rio de Janeiro: Contra Capa, 2011, p. 447-482, p. 468.

${ }^{46}$ MOREIRA, 2002a, p. 163.

${ }^{47}$ MARANHÃO VALLE, Sarah. O processo de destruição das aldeias na segunda metade do século XIX. In: OLIVEIRA, João Pacheco de (org.). A presença indígena no Nordeste. Rio de Janeiro: Contra Capa, 2011, p. 295-326.

${ }^{48}$ SILVA, Isabelle Braz Peixoto. O relatório provincial de 1863 e a expropriação das terras indígenas. In: OLIVEIRA, João Pacheco de (org.). A presença indígena no Nordeste. Rio de Janeiro: Contra Capa, 2011, p. 327-346, p. 335.
} 
privatização, no entanto, as terras de pastagem dos pueblos, que era de uso comum e indiscriminado entre os moradores, i.e., os ejidos. A constituição de 1857 foi mais enfática ainda no ideário de liquidação das terras de uso comum, proibindo expressamente a propriedade corporativa de bens imóveis e mandando repartir e privatizar também os ejidos que, até então, estavam excluídos do processo. ${ }^{49}$ Algumas interpretações sustentam que o alvo prioritário da Lei Lerdo não eram as terras das comunidades de índios e camponeses, mas principalmente aquelas imobilizadas como patrimônio corporativo da Igreja (Schenk 1995: 13, Ohmstede ; Rivas 2007: 263). ${ }^{50}$ Para Jan Bazant, por exemplo:

O principal aspecto da chamada "Lei Lerdo" foi a exigência de que a Igreja vendesse todas as suas propriedades rurais e urbanas a seus respectivos arrendatários e locatários com um desconto que tornasse atraente a transação para os compradores. Caso os eventuais compradores renunciassem aos seus direitos, a propriedade seria vendida em hasta pública pelas autoridades do governo. ${ }^{51}$

De acordo com Bazant, o liberalismo mexicano estava apostando, fundamentalmente, em uma estratégia de destruir a propriedade da Igreja e, ao mesmo tempo, fortalecer a propriedade privada. ${ }^{52}$ Desse ponto de vista, pode-se argumentar que o objetivo das reformas liberais não era expropriar índios e camponeses, mas antes extraí-los das formas de vida consideradas "atrasadas", "coloniais" ou "tradicionais" de suas coletividades (pueblos), transformando-os em cidadãos (modernos) com propriedade individual. Antonio Escobar Ohmstede e Ana María G. Rivas frisam, contudo, que pouco depois da Lei Lerdo, em 25 de junho de 1856, um regulamento datado de 30 de julho do mesmo ano estendia às comunidades indígenas a política de parcelamento e privatização das terras previstas na lei anterior para as corporações civis e eclesiásticas. Além disso, em carta escrita por Sebastián Lerdo de Tejada ao governador de Michoacán, ele afirmou abertamente que as comunidades indígenas não deviam ser toleradas, prescrevendo, por isso mesmo, que as terras fossem repartidas e privatizadas segundo o espírito da lei de 25 de junho. $^{53}$

As medidas desamortizadoras da legislação agrária mexicana, lançadas ao longo do século XIX e especialmente intensificadas a partir da Lei Lerdo, exalam a preocupação da elite política mexicana em constituir um mercado de terras e de trabalho no país. Assim, apesar das diferenças e disputas no interior dela, a privatização das terras comunais conseguiu apoio entre liberais e conservadores, pois a medida era importante para a modernização mexicana, ao permitir a circulação no mercado das terras e dos braços indígenas. ${ }^{54}$ A questão era, contudo, delicada e até mesmo potencialmente explosiva e, por

\footnotetext{
${ }^{49}$ BAZANT, Jan. O México da independência até 1867. In: BETHELL, Leslie (org.). História da América Latina: da Independência a 1870. São Paulo: Edusp, vol. III, 2009, p. 413-464, p. 451.

${ }^{50}$ SCHENK, Frank. La desamortización de las tierras comunales en el Estado de México (1856-1911). El caso del distrito de Sultepec". HMex, vol. XLV, n. 1, p. 3-37, 1995, p. 13. OHMSTEDE; RIVAS, Op. cit., p. 263

${ }^{51}$ BAZANT, Op. cit., p. 448

52 Ibidem, p. 426.

${ }^{53}$ OHMSTEDE; RIVAS, Op. cit., p. 263

${ }^{54}$ OHMSTEDE, 2007, p. 22.
} 
isso mesmo, sofreu também alguns reveses. Por exemplo, o príncipe austríaco Maximiliano tentou tirar partido da resistência indígena contra a repartição e privatização das terras do comum. Assim, com o objetivo de obter o apoio dos índios para seu "governo estrangeiro", mandou que fosse restituído aos povoados indígenas o direito de possuírem terras e, mais ainda, prometeu terras comunitárias aos pueblos que não as tivessem em quantidade suficiente. $^{55}$

Naturalmente, as leis e interesses modernizadores não criaram, da noite para o dia, uma nova ordem social e agrária e muito menos os índios ficaram passivos diante do processo desamortizador. Os liberais mexicanos tenderam a lastimar a "ignorância" dos índios, que pareciam não compreender as vantagens de possuírem individualmente a propriedade de suas terras. Mas o que eles qualificavam de "ignorância" era, na realidade, um conjunto variado de ações e estratégias desencadeadas pelos índios com o fito de impedir as reformas liberais, que não apenas privatizavam as terras do comum, como também arruinavam a relativa autonomia política e organizativa dos pueblos. Ignorar as leis e simplesmente não procurar as autoridades competentes para regularizar as tierras de común repartimiento foi uma das formas assumida pela resistência. Outra foi a recusa formal de atender às normas legais, segundo o argumento de que os terrenos possuídos eram propriedade legítima obtida no tempo do governo colonial. Outra ainda foi a revolta, pois, como observou Frank Schenk, mandar "medir y hacer divisiones en un pueblo recalcitrante era una empresa no solo custosa, sino arrisesgada, ya que podria desencadenar una rebelión". 56

Em resumo, a historiografia sobre o México reconhece que os processos de recepção e de mitigação das novas diretrizes, em âmbito local e regional, variaram bastante e contaram com a ativa resistência dos índios. Além disso, o efetivo impacto da legislação liberal sobre os pueblos de índios é assunto bastante controverso na literatura especializada. Alguns autores externam a dificuldade de opinar sobre o assunto, em razão da insuficiência de investigações regionais que sustentem uma avaliação de natureza global sobre o tema, enquanto outros defendem que, a partir da Lei Lerdo, ocorreu um desapossamento massivo dos índios e camponeses. ${ }^{57}$ Margarita Carbó exemplifica a segunda avaliação, já que para ela a legislação liberal mexicana provocou uma profunda reorganização no estilo de vida de índios e de camponeses, pois embora os pueblos tenham sobrevivido como corporações civis, mantiveram a posse de pouca terra:

El mapa del territorio mexicano había ido cambiando de fisionomia. Haciendas e ranchos fueram pintando com su propios colores los espacios que antes pintaban los de los pueblos de indios. A fin de siglo [XIX] el riesgo planteado al inicio de este artículo se habia concretado en una dolorosa realidad. Las corporaciones civiles, juridicamente inexistentes desde 1856 seguian ahí en gran número y representaban en torno al $30 \%$ de la población total, pero solo concervaban el $2 \%$

\footnotetext{
${ }^{55}$ BAZANT, Op. cit., p. 46.

${ }^{56}$ SCHENK, Op. cit., p. 25.

${ }^{57}$ Ibidem, p. 7.
} 
de la superfície de cultivo o pastoreo y el futuro se avisoraba aún mas negro, como efectivamente lo fue. ${ }^{58}$

Outros autores, segundo Frank Schenk, relativizam e modulam essa imagem, salientando tanto o impacto diferencial do processo de privatização nas diferentes regiões do país quanto a sobrevivência de muitas terras comunais devido à resistência pacífica ou armada das comunidades. ${ }^{59}$ Antonio Escobar Ohmstede e Ana María G. Rivas servem de exemplo, pois não apenas criticam o que eles qualificam de "leyenda negra" associada ao processo desarmotizador - segundo eles criada pelos intelectuais pós-revolucionários para caracterizar a ação do governo de Porfírio Díaz no campo ${ }^{60}$-, como apresentam alternativas utilizadas pelos índios para manter suas terras e sua autonomia. Dentre elas, a do "conduenazgos", i.e., uma forma condominial de posse e propriedade da terra, que ainda permitia aos condôminos desfrutarem um apreciável nível de autonomia política. ${ }^{61}$

A exemplo do México, as leis agrárias promulgadas no Brasil, a partir da segunda metade do século XIX, tinham também uma inequívoca ligação com o desideratum de fomentar um mercado de trabalho e de terras no país. ${ }^{62}$ Mas os desafios brasileiros na consecução desses objetivos eram bem diferentes daqueles enfrentados pela elite mexicana. Não é demais lembrar, por exemplo, que desde a Lei Eusébio de Queirós, em 1850, que aboliu o tráfico de escravos africanos para o Brasil, o maior problema vivido pela elite brasileira era criar um mercado de trabalho livre capaz de sustentar a economia agrárioexportadora ainda baseada na mão de obra servil. Para parte importante da historiografia, a Lei de Terras de 1850 teve o significado precípuo de estruturar a transição do trabalho escravo para o livre no país, pois, a partir da nova lei, o acesso às terras públicas, também nominadas de "terras devolutas", dar-se-ia exclusivamente mediante a compra. ${ }^{63} \mathrm{~A}$ expectativa era de que os custos financeiros envolvidos na compra e a demarcação de terras dificultassem que a população nacional e imigrante tivesse acesso à propriedade territorial e formasse uma classe camponesa independente e avessa à prestação de serviços aos grandes produtores rurais. Em outras palavras, a "impossibilidade de ocupação sem pagamento das terras devolutas, recriava as condições de sujeição do trabalho que desapareceriam com o fim do cativeiro". ${ }^{64}$

Bem diferente do México, a desamortização de terras da Igreja e das corporações civis nunca possuiu a mesma importância e centralidade para o projeto modernizador da estrutura agrária brasileira e os únicos alvos efetivos da política de desamortização desencadeada pelo Segundo Reinado (1840-1889) foram os índios. As terras corporativas da Igreja, por exemplo, foram mantidas praticamente intocadas, pois, de acordo com Raquel

\footnotetext{
${ }^{58}$ CARBÓ, Margarita. De la republica de indios a la corporación civil. Viver bajo permanente amenaza. Scritpta NovaRevista Eletrónica de Geografía e Ciencias Sociales. Barcelona, vol. X, n. 218 (73), p. 1-11, 2006, p. 9.

${ }^{59}$ SCHENK, Op. cit., p.7.

${ }^{60}$ OHMSTEDE; RIVAS, Op. cit., p. 253.

${ }^{61}$ Ibidem, p. 280.

${ }^{62}$ MARTINS, José de Souza. O Cativeiro da Terra. 6. ed. São Paulo: Hucitec, 1996. SILVA, 1996.

${ }^{63}$ SILVA, 1996, p. 35

${ }^{64}$ MARTINS, Op. cit., p. 29
} 
Glezer, ainda não foi encontrada "determinação imperial para a desapropriação ou venda de bens de ordens religiosas, recolhimentos, irmandades ou confrarias; caso tenham existido, os indícios são de que foram soluções tópicas locais e não gerais" ${ }^{65}$

No caso das terras das corporações civis, o regime imperial fez uma intervenção mais liberalizante, mas também bastante pontual. Transformou os antigos conselhos das vilas e cidades coloniais em câmaras municipais, pela lei de 1 de outubro de 1828, mas não alterou, por exemplo, a situação dos "campos de uso comum", permitindo que eles fossem mantidos para o uso dos moradores das freguesias, municípios ou comarcas. ${ }^{66}$ Mais ainda, as terras dos termos das antigas vilas - i.e., seis léguas ou 39,6 km - também foram mantidas como patrimônio corporativo dos municípios. Com a Lei de Terras, o que mudou é que as terras do termo das antigas vilas poderiam ser vendidas ou aforadas pela municipalidade, exceto aquelas que estivessem ocupadas, cujos moradores ficaram obrigados a registrá-las. Em resumo, na avaliação de Raquel Glezer, apesar do caráter liberal da Lei de Terras de 1850 , em muitos aspectos a nova lei permitiu a reprodução do sistema de posse territorial do Antigo Regime, pois

[...] as corporações religiosas mantiveram as propriedades de "mão-morta", e, as câmaras municipais continuaram detentoras de patrimônio; os "campos de uso comum" foram mantidos, bem como os arrendamentos, cujos foros e laudêmios deveriam fornecer renda às municipalidades. ${ }^{67}$

Como ainda salientou a autora em uma nota de rodapé, o "processo de desamortização no país parece só ter ocorrido nas áreas de aldeamentos indígenas [...]". ${ }^{68}$ Deve-se acrescentar, além disso, que a política imperial de desamortização das terras dos índios foi bastante sistemática e agressiva e teve início imediato a partir da Decisão n. 992 de 21/10/1850, publicada apenas um mês depois da Lei de Terras, cuja orientação era a de incorporar aos próprios nacionais as terras de descendentes de índios que estivessem "confundidos na massa da população civilizada". ${ }^{69}$ A Decisão n. 92 também recomendou que apenas se considerassem "devolutas" - i.e., "vagas" e por isso mesmo pertencentes aos "próprios nacionais" - as terras que não estivessem ocupadas sob qualquer título que fosse, até que o governo resolvesse sobre a validade ou não daquelas posses e arrendamentos em terras indígenas.

Depois da Decisão n.o 92, foram desativadas diversas aldeias em todo o Império, sempre segundo a justificativa de estarem elas abandonadas, sem reais representantes da população indígena ou porque os índios já estariam misturados com a população geral. ${ }^{70} \mathrm{~A}$ resolução oficial sobre o que fazer com as posses e aforamentos em terras indígenas

\footnotetext{
${ }^{65}$ GLEZER, Raquel. Persistência do Antigo Regime na legislação sobre a propriedade territorial urbana no Brasil: o caso da cidade de São Paulo (1850-1916). Revista Complutense de Historia de América, vol. 33, p. 197-215, 2007, p. 203.

${ }^{66}$ Ibidem, p. 204 e 207

${ }^{67}$ Ibidem, p. 213.

68 Ibidem, p. 210.

${ }^{69}$ Decisão n.o 92 de 21/10/1850. In: CUNHA, 1992b, 213.

${ }^{70}$ CUNHA, 1992b, p.22.
} 
finalmente apareceu em 1860. De acordo com a lei n. 1.114, de 27 de setembro de 1860, em seu Art. 11, § 8, o governo ficou autorizado a

aforar ou vender, na conformidade da lei n. 601 de 18 de setembro de 1850, os terrenos pertencentes às antigas Missões e Aldeias dos índios, que estiverem abandonadas, cedendo, todavia, a parte que julgar suficiente para a cultura dos que neles ainda permanecerem, e os requererem. ${ }^{71}$

Com a lei n.o 1.114, portanto, o governo procurou desamortizar as terras indígenas, dando poderes discricionários ao governo para aforá-las, vendê-las ou repartir parte delas aos índios que as requeressem. Note-se, ademais, que essa orientação oficial foi seguida até os últimos dias do regime imperial e não significava, necessariamente, expropriar os índios como "indivíduos", mas apenas como "comunidades", pois lhes ficou reservado o direito a terem parcelas de terra como propriedades individuais, desde que, no entanto, eles fossem classificados como "índios" pelas autoridades. É isso que está expresso nas orientações normativas do período, como a Resolução Oficial n. o 29, de 19 de maio de 1862, que autorizou o presidente da Província de São Paulo a extinguir os aldeamentos:

[...] distribuindo a cada família no ponto, onde já possua casa e lavoura, bem como aos solteiros maiores de vinte e um annos, que tenham economia separada, terreno sufficiente que não abranja mais de sessenta e duas mil e quinhentas braças quadradas e seja em geral de vinte e duas mil e quinhentas, que ficarão sendo propriedade desses indivíduos depois de cinco annos de effetiva residência e cultura $[\ldots] .^{72}$

Ainda de acordo com a Resolução n.o 29, de 19 de maio de 1862, a medida se justificava porque à "[...] vista das informações offerecidas pelo Director Geral de Índios dessa Província [de São Paulo], convenceu-se o Governo Imperial de que ahi existem muitos aldeamentos formados de indivíduos, que, pela mór parte, somente de Índios tem o nome [...]". ${ }^{73}$ O mesmo, ademais, aconteceu em outras partes do Império como o Ceará, Pernambuco e Espírito Santo. ${ }^{74}$

A existência simultânea de ações em prol da liquidação de aldeamentos, por meio da desamortização e da privatização de suas terras, ao lado de outras favoráveis à manutenção ou à criação de outros aldeamentos não é testemunho de "contradição" ou "ambiguidade" na política indigenista imperial, como ainda insistem certas interpretações. ${ }^{75}$ Os aldeamentos e missões, ou a "colonização indígena", eram recomendados aos índios ainda não conquistados e ressocializados ou, em termos de época, aos grupos e indivíduos pertencentes às "hordas selvagens". Nesses termos, aldeamentos e terras coletivas deveriam ter uma existência pontual, transitória e provisória. Quanto aos índios

\footnotetext{
${ }^{71}$ Lei n.o 1114, de 27/09/1860. In: CUNHA, 1992b, p. 257.

72 19/05/1862: n.o 29 - Agricultura, Commercio e Obras Públicas - Manda extinguir aldeamentos, dando diversas providências. In: CUNHA, 1992b, p. 258.

${ }^{73}$ Ibidem, p. 258.

${ }^{74}$ SILVA, 2011; VALLE, 2011; MARANHÃO VALLE, 2011; e MOREIRA, 2002a.

${ }^{75}$ SILVA, 2011, p. 331.
} 
considerados ressocializados, eles deveriam ser introduzidos na ordem social como "brasileiros" e quiçá também como "cidadãos", ordenando-se que as terras coletivas fossem desamortizadas, repartidas e privatizadas.

A manutenção ou liquidação de aldeias ou posses coletivas ficava na dependência, portanto, das avaliações subjetivas das autoridades, que deveriam arbitrar se os índios estavam ou não suficientemente ressocializados, e das circunstâncias e relações de poder locais, por meio das quais os índios podiam ter mais ou menos poder de influência ou contar ou não com aliados. Mas nas novas condições legais impostas aos índios, na melhor das hipóteses, eles poderiam possuir apenas parcelas de terras individuais, engrossando a categoria social dos pequenos lavradores, caso fossem considerados "remanescentes" ou "descendentes" de índios, requeressem esse direito e contassem com o apoio das autoridades locais para a demarcação e registro de suas terras.

Em resumo, desde os primeiros anos do novo regime existiu uma tendência de atribuir aos índios considerados ressocializados a condição de brasileiros e cidadãos. Tratava-se de um procedimento político realizado "de cima para baixo", de acordo com os interesses das elites nacionais e locais e, por isso mesmo, pode-se considerar que os índios passaram por um processo mais ou menos forçado de "nacionalização" e "cidanização". Se isso foi bom ou se eles desejavam passar por isso são questões muito diferentes, cuja adequada discussão e abordagem exigiria, naturalmente, outro artigo. Não é demais frisar, contudo, que as evidências demonstram que o regime imperial impôs aos índios uma autoritária e radical transição do Antigo Regime para a nova ordem liberal. Em termos concretos, isso significou que os índios, que durante o período colonial podiam combinar e acumular diferentes noções de pertencimento, identidade e lealdades - especialmente a de índios, cristãos e súditos do reino - foram instados a assumir uma classificação e lealdade única: a de cidadãos brasileiros, perdendo antigos privilégios, como o direito coletivo de domínio sobre as terras dos aldeamentos, e nem sempre ganhando vantagens compatíveis às perdas sofridas. ${ }^{76}$ Por isso mesmo, a historiografia mais identificada com o ponto de vista dos índios tende a considerar o período imperial como especialmente nefando para eles.

Para Carlos de Araújo Moreira Neto, por exemplo, a política indigenista da segunda metade do século XIX, i.e., do Segundo Reinado, foi guiada pelo liberalismo econômico e pela Lei de Terras, tornando-se subordinada à "política geral de alienação de terras públicas e de colonização, em si mesmas diametralmente opostas aos mais elementares interesses e direitos dos índios". ${ }^{77}$ Moreira Neto é, na realidade, um crítico acérrimo da política indigenista imperial, qualificando-a, no seu conjunto, como "anti-indígena", em razão dos efeitos depopulativos e dissociativos da ação e/ou omissão do estado imperial em relação aos índios e às comunidades indígenas. Afinal, o estado deliberadamente dissolveu aldeamentos e a posse comum das terras indígenas e foi ineficiente na proteção dos índios contra toda a sorte de "extorsões, crimes e agravos"

\footnotetext{
${ }^{76}$ MOREIRA, 2010, p. 136.

${ }^{77}$ MOREIRA NETO, Op. cit., p. 274.

78 Ibidem, p. 285.
} 
pois, para o autor, durante o regime imperial, os índios perderam "seu lugar na História Nacional, para se recolherem a um estado de marginalidade e de progressiva diminuição populacional [...]". ${ }^{79}$ Na mesma linha, Manuela Carneiro da Cunha afirma que durante o Império os índios foram "destruídos"

[...] por processos mesquinhos e sem vozes dissonantes [...]. Não é de se estranhar, por isso, que boa parte do debate até os anos 60 do século XIX se tenha travado em torno não dos fins de uma política indigenista, e sim de seus meios: se se deviam exterminar sumariamente aos índios, distribuí-los aos moradores, ou se deviam ser cativados com brandura. ${ }^{80}$

Como se pode ver, no âmbito da historiografia sobre os índios e o indigenismo, o Império não goza de boa reputação e, em grande parte, esse juízo existe em razão das medidas desamortizadoras adotadas pelo regime que, após a promulgação da Lei de Terras, fizeram deslanchar o processo de extinção de várias aldeias e o repartimento e privatização de muitas terras indígenas, produzindo uma avassaladora pressão dissociativa em várias comunidades e grupos indígenas. Estudos mais recentes, aliás, continuam corroborando o caráter "anti-indígena" da política imperial, tal como o de Sarah Valle, para quem houve na Província de Pernambuco um processo de destruição das aldeias na segunda metade do século XIX, devido à "legislação anti-indigenista do Império", pois a aplicação das leis agrárias na província, segundo a autora, não visou à demarcação e à legitimação das terras das aldeias, mas antes à sua extinção. ${ }^{81}$

É importante ponderar, contudo, que por mais que o período imperial tenha sido nefando para os índios, a convicção de que eles foram "destruídos" por um regime que não tinha um projeto político claro não se sustenta, não apenas porque a ação humana não se faz no vácuo moral e normativo ${ }^{82}$, mas também porque subjacente à desativação de aldeamentos e à desamortização das terras indígenas estava o liberalismo, o nacionalismo e seus princípios normativos. Um efeito "eye-opening" importante que emerge da comparação entre as realidades do México e do Brasil é, portanto, o de tornar visível que aquilo que a historiografia tem qualificado de "a política anti-indigenista imperial" é, fundamentalmente, um modelo autoritário de ação indigenista. Apoiado no novo campo normativo liberal e nacionalista em ascensão, esse modelo deslegitimava a existência de comunidades etnicamente diferenciadas no interior do território e, por isso mesmo, parcelava e privatizava as terras dos índios, reclassificando-os como "brasileiros", "nacionais" ou "cidadãos".

\footnotetext{
79 Ibidem, p. 21.

${ }^{80}$ CUNHA, 1992a, p. 5

${ }^{81}$ MARANHÃO VALLE, Op. cit., p. 320 e 307.

${ }^{82}$ SKINNER, Quentin. As fundações do pensamento político moderno. São Paulo: Companhia das Letras, 2006, p. 12.
} 


\section{CONSIDERAÇÕES FINAIS}

A comparação entre as realidades do México e do Brasil torna visível o enorme impacto do novo campo normativo liberal e nacionalista sobre a reorganização da política indigenista ao longo do século $\mathrm{XIX}$, quando ambos os países passaram por um longo processo de organização do estado e da sociedade nacional. Para os índios, isso significou não somente modificações importantes no sistema de posse e propriedade de suas terras, mas também a "nacionalização" mais ou menos forçada de muitas comunidades, cujos membros tenderam a ser reclassificados como mexicanos e brasileiros. $O$ fato de o regime imperial brasileiro apenas desamortizar as terras corporativas dos índios, permitindo a sobrevivência das terras corporativas civis e religiosas, mostra bem o quanto o ideário liberal e nacionalista foi implacável contra os índios, tentando destruir sua organização social e sua relativa autonomia, rompendo as fronteiras étnicas e sociais entre eles e as sociedades locais envolventes. Desse ponto de vista, a política indigenista imperial está muito longe de ser uma mera continuidade natural do antigo regime colonial.

Que a política liberal e nacionalista afetou, e muito, a vida dos índios e das comunidades indígenas não restam dúvidas, embora a historiografia ainda esteja longe de um balanço seguro sobre como a "nacionalização", a "cidanização" e a desamortização afetaram os índios das diferentes regiões, localidades e grupos étnicos e culturais, nem tampouco como cada grupo ou comunidade respondeu à nova ordem social e política liberal. No entanto, o interesse em perceber como os índios reagiram à maré liberal e, mais ainda, como eles exploraram as novas possibilidades abertas pela "'cidanizazação" são preocupações que estão cada vez mais sendo pautadas como eixos importantes das investigações sobre o tema. ${ }^{83}$

Não é demais terminar salientando o principal efeito "eye-opening" da comparação entre México e Brasil nesta reflexão, pois espero que tenha ficado em evidência a importância da política para a vida dos índios. Tanto da política estatal e liberal, que redesenhou os princípios norteadores da ação política em relação aos índios, quanto da política local, i.e., da correlação entre municipalização, perda do poder local pelos índios e recrudescimento do processo de expropriação e privatização das terras que a eles pertenciam.

Recebido em 05/08/2012

Aceito para publicação em 01/10/2012

\footnotetext{
${ }^{83}$ MOREIRA, 2010. OHMSTEDE, Antonio Escobar. Ha variado el sistema gubernativo de los pueblos. ¿La ciudadania gaditana y republicana fue imaginaria? para los indígenas. Uma vusiõn desde los Huastecas". In: SANDOVAL, María del Carmen Salinas; GARDIDA, Diana Birrichaga; OHMSTEDE, Antonio Escobar (coords.). Poder y gobierno local en México, México, Colegio de Michoacán, 2011, p. 151-192.
} 